\title{
Micro-structural evolution and their effects on physical properties in different types of tectonically deformed coals
}

\author{
Yiwen Ju $\cdot$ Kray Luxbacher $\cdot$ Xiaoshi Li $\cdot$ Guochang Wang $\cdot$ Zhifeng Yan $\cdot$ Mingming Wei $\cdot$ Liye Yu
}

Received: 25 October 2013/Revised: 5 May 2014/Accepted: 8 May 2014 / Published online: 29 October 2014

(C) The Author(s) 2014. This article is published with open access at Springerlink.com

\begin{abstract}
The macromolecular structure of tectonically deformed coals (TDC) may be determined by the deformation mechanisms of coal. Alterations of the macromolecular structure change the pore structure of TDC and thereby impact physical properties such as porosity and permeability. This study focuses on structure and properties of TDC from the Huaibei and Huainan coal mining areas of southern North China. Relationships between the macromolecular structure and the pore structure of TDC were analyzed using techniques such as X-ray diffraction, high-resolution transmission electron microcopy, and the low-temperature nitrogen adsorption. The results indicated that the directional stress condition can cause the arrangement of basic structural units (BSU) more serious and closer. And, the orientation is stronger in ductile deformed coal than in brittle deformed coal. Tectonic deformation directly influences the macromolecular structure of coal and consequently results in dynamic metamorphism. Because the size of BSU in brittle deformed coal increases more slowly than in ductile deformed coal, frictional heating and stress-chemistry of shearing areas might play a more important role, locally altering coal structure under stress, in brittle deformed coal. Strain energy is more significant in increasing the ductile deformation of coal. Furthermore, mesopores account for larger percentage of the nano-scale pore volume in brittle deformed coals, while mesopores volume in ductile deformed coal diminishes rapidly along with an increase in the proportion of micropores and sub-micropores. This research also approved that the deformations of macromolecular structures change nano-scale pore structures, which are very important for gas adsorption and pervasion space for gas. Therefore, the exploration and development potential of coal bed methane is promising for reservoirs that are subjected to a certain degree of brittle deformation (such as schistose structure coal, mortar structure coal and cataclastic structure coal). It also holds promise for TDC resulting from wrinkle structure coal of low ductile deformation and later superimposed by brittle deformation. Other kinds of TDC suffering from strong brittle-ductile and ductile deformation, such as scale structure coal and mylonitic structure coal, are difficult problems to resolve.
\end{abstract}

Keywords Tectonically deformed coals - Formation mechanisms - Macromolecular structure Pore structure Micro-structured evolution $\cdot$ Coal bed methane

\section{Introduction}

Y. Ju $(\bowtie) \cdot$ X. Li $\cdot$ G. Wang $\cdot$ Z. Yan $\cdot$ M. Wei $\cdot$ L. Yu

Laboratory of Computational Geodynamics, College of Earth

Science, University of Chinese Academy of Sciences,

Beijing 100049, China

e-mail: juyw03@163.com

K. Luxbacher

Department of Mining \& Minerals Engineering, Virginia Tech, Blacksburg, VA 24061, USA
At present, most researches about coal primary structure are concerned with the microstructure, chemical structure and elemental variation (Qin 1994; Han 1996; Hower 1997; Zickler et al. 2006; Green et al. 2011; Castro et al. 2012). Microstructure, chemical structure and elemental variation can change the primary structure of coal when influenced by temperature and pressure. The tectonically deformed coals (TDC) is a kind of coal that ever underwent 
mono- or multi-phase tectonic stress fields, with which the primary texture and structure of TDC are deformed, broken or destroyed. Previous researches focused on observing structural form of TDC (Wang and Zhu 1988; Li and Zhong 1992; Li et al. 2013). In recent years, researchers have conducted some preliminary investigations regarding the macromolecular structure, the elemental variation and dynamic metamorphism of TDC (Cao et al. 2000, 2002; Xu et al. 2004; Ju et al. 2005a). In addition, much more attention is increasingly placed on the stress influence on nano-scale structural deformation. Structural deformation can influence the macromolecular structure (chemical structure) of coal and enhance coalification to a certain degree (Teichmüller 1987; Nishioka 1992; Fowler and Gayer 1999; Cao et al. 2000; Ju et al. 2005a, b; Li et al. 2011, 2012, 2013).

Stone and Cook (1979) suggested that anisotropic stress may influence coalification by imparting strain to vitrinite during coalification. Teichmüller and Teichmüller (1966), Bustin (1983) and Suchy et al. (1997) concluded that local increases of coal rank and local graphitization were resulted from frictional heating. Levine and Davis (1989) assumed that the applied stress field caused the increase of bireflectance by the preferred nucleation and growth of favorably oriented lamellae. Based on XRD, TEM and Micro-Raman spectroscopy evaluations, Ju et al. (2005c) concluded that the shearing stress causes the stacking height of aromatic lamellae of coal structure and also leads to the elongation and contraction of pores between the aromatic lamellae. Observations of increased vitrinite reflectance or local coalification can be classified as either a temperature effect (Teichmüller and Teichmüller 1966; Bustin 1983; Suchy et al. 1997) or a mechanical strain mechanism (Stone and Cook 1979).

Levine and Davis (1989) postulated a mechanicalchemical mechanism in which stress reorients the lamellae and facilitates growth of aromatic structure. Bustin et al. (1995) and Ross and Bustin (1990), on the other hand, thought strain energy transformation played an important role in graphitization of coal under the shear stress regime. Several previous studies concerning ductile deformation demonstrated that the size of aromatic stacks and vitrinite reflectance increases in TDC (Jiang and Qin 1998; Cao et al. 2000; Ju et al. 2005b; Li et al. 2013). Although significant progress has been made in recent years, a few fundamental questions remain unclear concerning the development of TDC. For instance, how the different mechanisms (brittle and ductile deformation) affect the structural and composition characteristics of TDC? TDC often shows distinct degrees of brittle and ductile deformation because of different deformation mechanisms. The roles of frictional heating and strain energy in brittle and ductile deformation and their relative importance have not been characterized clearly. Structural deformation can not only further alter coal molecular structure to different degrees, but also change the physical properties of coal reservoirs (porosity and permeability). Structural deformation can alter both macromolecular structure and pore structure of coals. Based on measurements of mercury intrusion, researchers have compared micropore features of TDC collected from different coalfields, and they thought that TDC contained greater medium pore volumes than normal coal (Wang and Yang 1980; Yao and Lu 1996; Zhang et al. 1996). No difference in mesopores and micropores was found, which indicated that structural deformation did not significantly influence micropore structure (Yao and Lu 1996; Zhang et al. 1996; Hower 1997). However, Ju et al. (2005c) concluded that structural deformation can not only change the micropore structure $(5-15 \mathrm{~nm})$ of coal, but also influence sub- and ultramicropore structure $(<5 \mathrm{~nm})$, which is the main adsorption space for coal bed methane. Meanwhile, the nano-scale pore structure of TDC provides the main adsorption space for CBM, and macromolecular structure is an important factor for restricting the adsorption capacity in coal. Therefore, the problem of macromolecular structure and nano-scale pores in TDC is a worthy research topic (Gan et al. 1972; Gregg and Sing 1982; Gürdal and Yalçin 2001; $\mathrm{Li}$ et al. 2012). Furthermore, gas adsorption/desorption behavior, as well as the permeability of micropores in coal, has strong effects on the occurrence and distribution of CBM (Evans and Brown 1973; Yuan 1985; Cao 1999; Jiang et al. 2001; Ju and Wang 2002; Ju 2003; Jiang et al. 2004; Ju et al. 2004).

The structure and chemical composition of coal alter regularly along with structural deformation due to the differences in the property, mode, and intensity of stress and the deformational environment. Moreover, the physical properties of TDC reservoirs vary significantly (Ju 2003; Ju et al. 2005a). Therefore, comprehensive studies on stress action, strain environment, physical and chemical structures of TDC and physical properties of TDC reservoirs are of great help in better understanding the theoretical basis for the exploration and evaluation of CBM resources and the prevention and control of coal and gas outbursts. In this paper, we discussed the structure of tectonically deformed metamorphic coals and the physical properties of TDC reservoirs using integrative techniques such as the optical microscope photometer, X-ray diffraction (XRD), electron paramagnetic resonance (EPR), nuclear magnetic resonance (NMR), coal vitrinite reflectance $\left(R_{\mathrm{O}, \max }\right)$ analysis, low-temperature nitrogen gas adsorption and scanning electron microscopy (SEM). Through comparing different mechanisms of TDC from different coal mines, we built the relationships between the macromolecular structure and the physical properties of TDC and explained how the primary deformation mechanisms are for these TDC. 


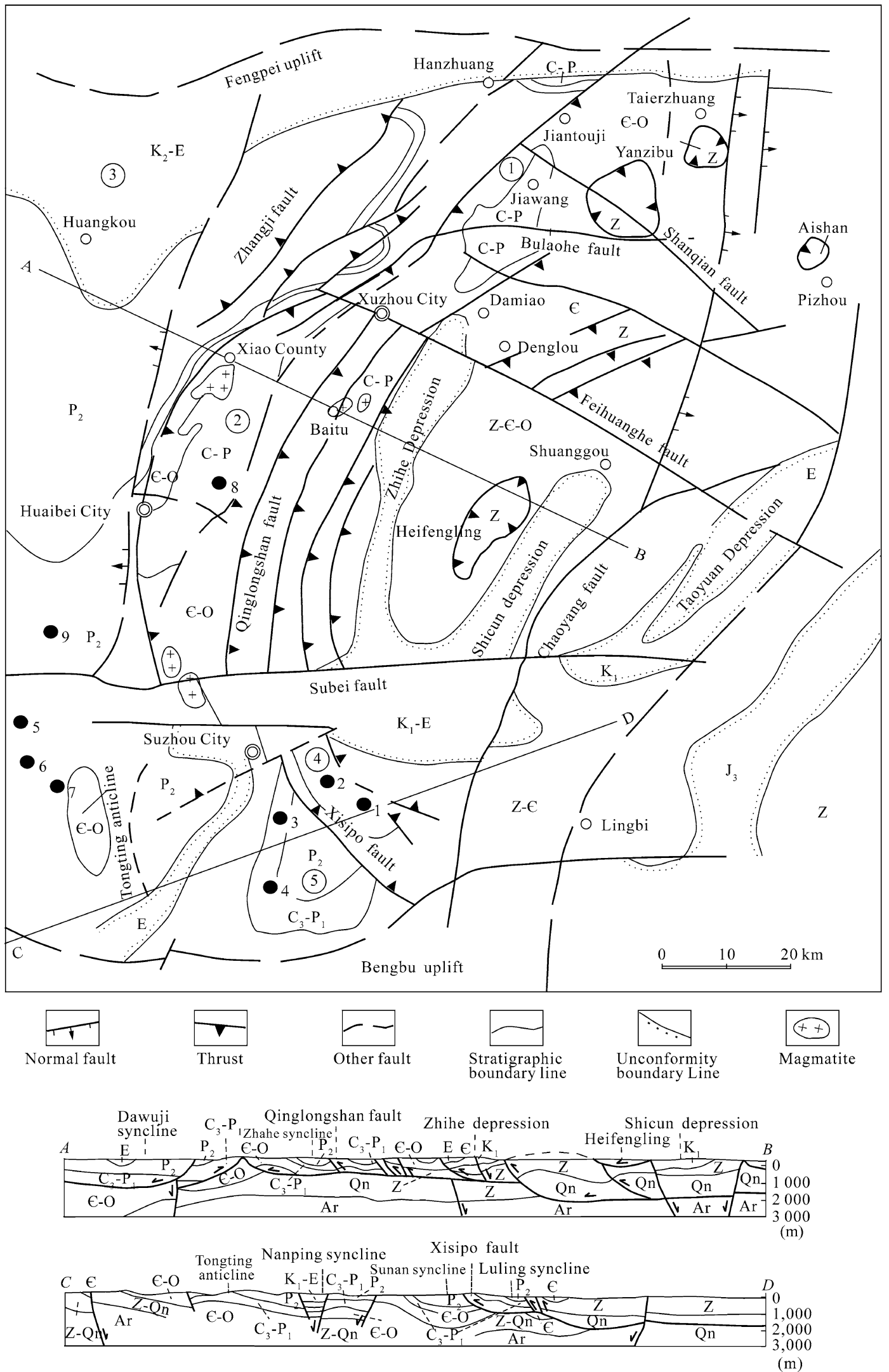


4Fig. 1 Schematic map showing the Xuzhou-Suzhou (Huaibei area) arcuate duplex-imbricate fan thrust system and sampling localities (modified from Wang et al. 1998). Encircled 1 Jiawang Syncline; Encircled 2 Zhahe Syncline; Encircled 3 Dawuji Syncline; Encircled 4 Sudong Syncline; Encircled 5 Sunan Syncline. 1 Luling coal mine in Suzhou mine area; 2 Zhuxianzhuang coal mine in Suzhou mine area; 3 Taoyuan coal mine in Suzhou mine area; 4 Qinan coal mine in Suzhou mine area; 5 Haizi coal mine in Linhuan mine area; 6 Linhuan coal mine in Linhuan mine area; 7 Tongting coal mine in Linhuan mine area; 8 Shitai coal mine in Suixiao mine area; 9 Baishan coal mine in Suixiao mine area

\section{Geologic background of the sampling area}

The Paleozoic coal-bearing basins, especially in North and South China, underwent multi-phase complicated structural evolution of compressing, shearing and extending. Thus, the variation of the primary structure of coal occurred at different degrees, causing wide development of different types of TDC. Previous researches in China indicated that TDC was an important factor in restricting the exploration and development of CBM, which is also a direct cause of gas outbursts of coal mines.

In the Huaibei and Huainan coalfields situated in the southern North China Plate (Figs. 1 and 2), coal measures contain Carboniferous-Permian (Paleozoic) systems, which were structurally influenced dominantly by the tectonic movements in Mesozoic. The main coal-bearing areas are found in fault depression basins, especially in the syncline structure. The uplift area between depression basins has undergone destruction and denudation. The faults and folds in the coal measures area have given rise to obvious breakages and deformations in the coal seams, leading to changes of the coal structure. At the end of this process, different types of TDC were formed, such as cataclastic structure coal, mortar structure coal, schistose structure coal, mealy structure coal, and even wrinkle structure coal and mylonitic structure coal (Ju et al. 2005a).

Huaibei coal mine region and the three mine areas in Huainan coal mine areas, including the Xinji mine region, Zhangji mine region and Panji mine region, represent different structural deformation units. The coal sample sets were collected from the Huaibei and Huainan coalfields (Figs. 1 and 2). These samples belong to different kinds of TDC, suffering from multi-phase structural deformation and magmatic events.

\section{Experimental methods}

In this study, two aspects were mainly taken into account in the selection of coal samples. The first aspect was coal rank, where $R_{\mathrm{o} \text {, max }}$ ranges from $0.76 \%$ to $3.59 \%$, including low, middle and high metamorphic coal. The second aspect is the structural characteristic of TDC formed by different mechanisms. Based on the results of the in situ measurement of coal mines and microstructural

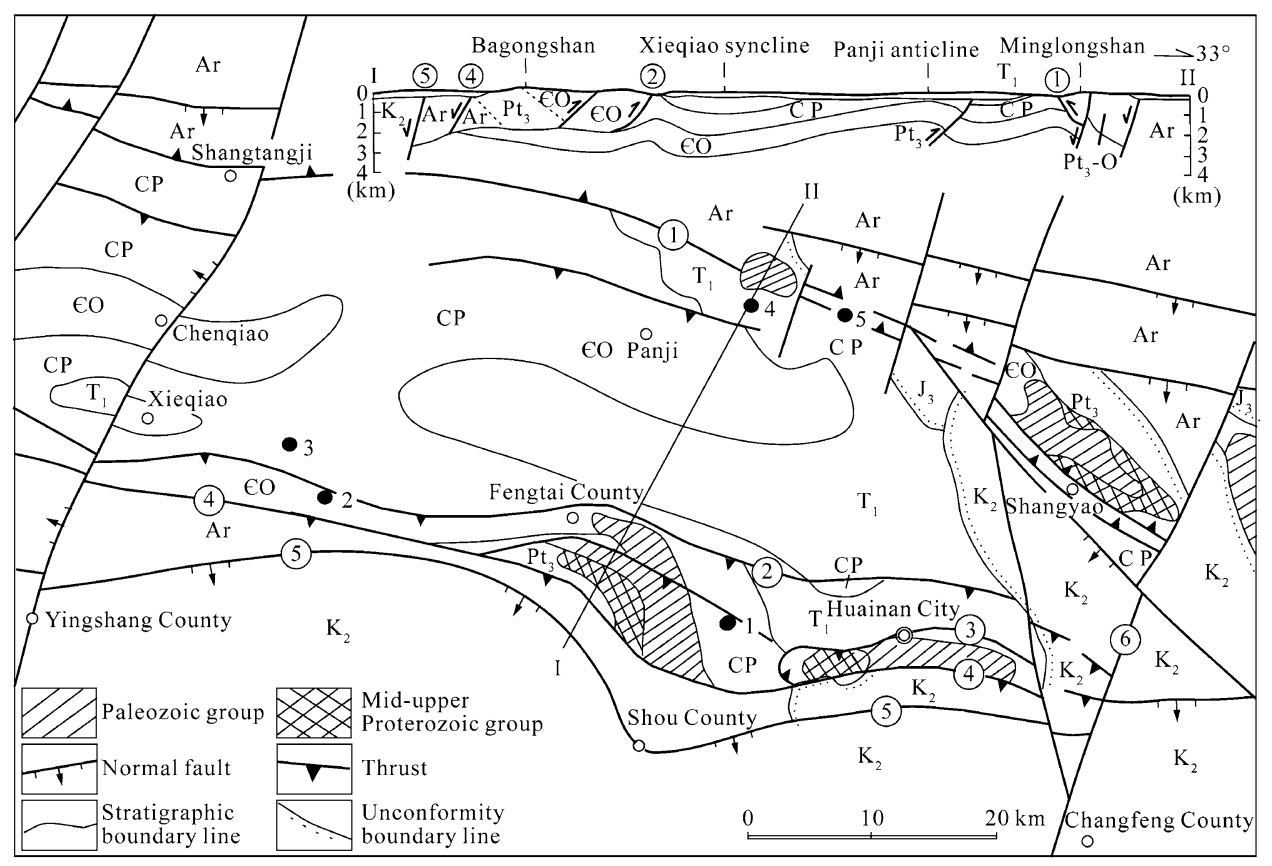

Fig. 2 Schematic map showing the thrust and nappe system in Huainan area and sampling localities (modified from Wang et al. 1992). Encircled 1 Shangtangji thrust; Encircled 2 Fufeng thrust; Encircled 3 Shungengshan thrust; Encircled 4 Fuli thrust; Encircled 5 Shou-Dingyuan normal fault; Encircled 6 Lingbi-Changfeng transfer fault. 1 Xieji No.1 coal mine in Xieji mine area; 2 Xinji No.1 coal mine in Xinji mine area; 3 Zhangji coal mine in Zhangji mine area; 4 Panji No.1 coal mine in Panji mine area; 5 Panji No.2 coal mine in Panji mine area 

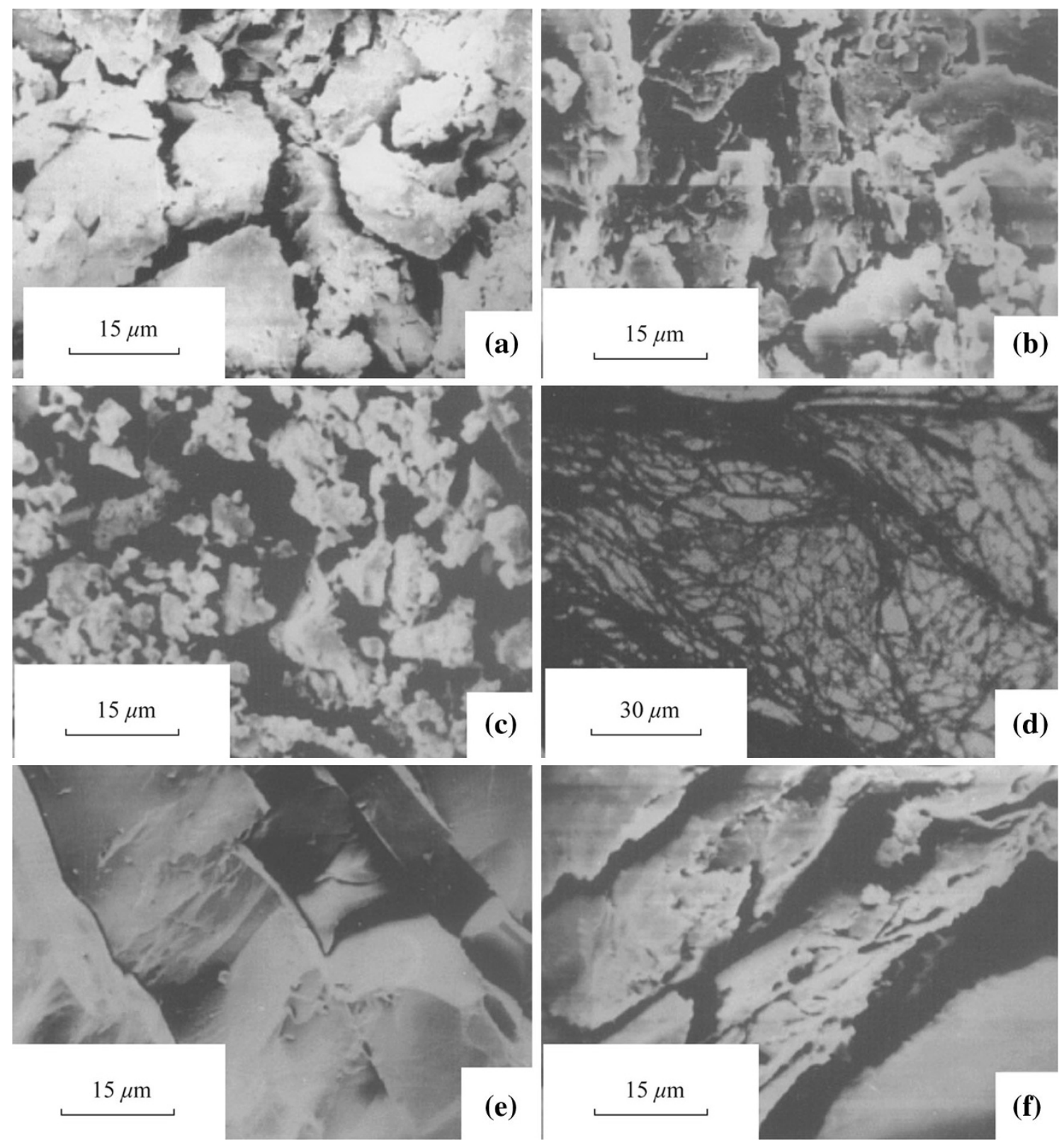

Fig. 3 The series of brittle deformations include. a Cataclastic structure coal; b Mortar structure coal; c Granulitic structure coal; d Mealy structure coal; e Schistose structure coal; f Thin-layer structure coal

observation, a structural-genetic classification system of TDC has been recommended to be applied not only to the exploitation of CBM (Ju et al. 2005c), but also to the prevention and control of coal and gas outbursts. TDC formed by different deformational mechanisms have been divided into three deformation series and ten classes ( $\mathrm{Ju}$ and Li 2009; Figs. 3, 4, 5). The brittle deformation series includes cataclastic structure coal, mortar structure coal, granulitic structure coal, mealy structure coal, schistose structure coal, and thin-layer structure coal; the brittleductile series includes scaly structure coal; the ductile deformation series includes wrinkle structure coal, mylonitic structure coal and ductile structure coal. The samples of brittle deformation series, ductile deformation series and brittle-ductile deformation series were selected separately.

Because of different depositional and tectonic environments, coal usually contains different maceral compositions and various kinds of mineral components, which greatly affect the results of coal structural testing. Therefore, coal samples must be pretreated to extract vitrinite components and remove inorganic (mineral) components before testing and analysis. Based on in situ (the coal sample was basically intact) investigation, detailed micro-structural observations 


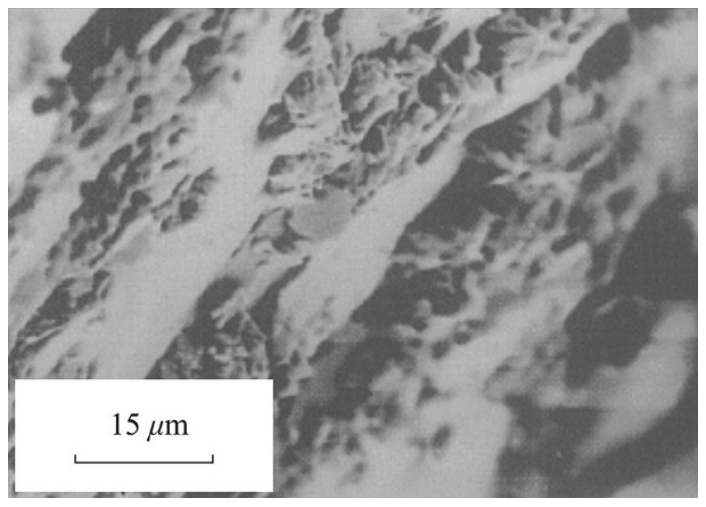

Fig. 4 The series of brittle-ductile transitions include only scale structure coal

of these samples, using optical microscopy and SEM, vitrinite reflectance analysis, were carried out on polished sections under halogen lamp and oil immersion conditions using a Leitz Orthoplan/MPV-SP microscope photometer.

In this study, systematic research was conducted on the characteristics of the macromolecular and chemical structure of different kinds of TDCs by using XRD, HRTEM, EPR, and NMR. The instrument used for XRD testing was a D/Max-IIIB X-ray diffractometer, which is made by Rigaku Inc. in Japan; the HRTEM instrument was a JEM2010, made in Japan by JEOL Inc.; the instrument used for EPR testing was an E-109 EPR spectrometer, made by Varian Inc. in the United States; the instrument used for NMR testing was the Infinity 400 NMR spectrometer, also made by Varian Inc. in the United States. The experimental conditions of the different instruments are the same as those in Ju et al. (2005a).

The pore characteristics of TDC have been determined by the low-temperature nitrogen adsorption method and SEM. The permeability has been analyzed through experiments of in-lab permeability measurements of large diameter, in situ samples from TDC.

The low-temperature liquid nitrogen adsorption experiments were run in the ASAP-2010, made in the United States by Micromeritics Instrument Inc., to measure the micropore specific surface area and pore size distribution. The permeability measurement was completed in the whole-core flow system, made by Terra Tek Corporation. The whole-core flow system was primarily used to simulate crustal pressure and rock permeability under natural oil reservoir pressures. The highest simulated crustal and fluid pressures were 70 and $65 \mathrm{MPa}$, respectively. In this study, we tested the single-phase permeability of helium $(\mathrm{He})$ and methane $\left(\mathrm{CH}_{4}\right)$ at room temperature $\left(25^{\circ} \mathrm{C}\right)$ and at an effective constant pressure of $2 \mathrm{MPa}$. The pressure under stratigraphic conditions was 7.0 $\mathrm{MPa}$, and the test data were similar to the in situ stress
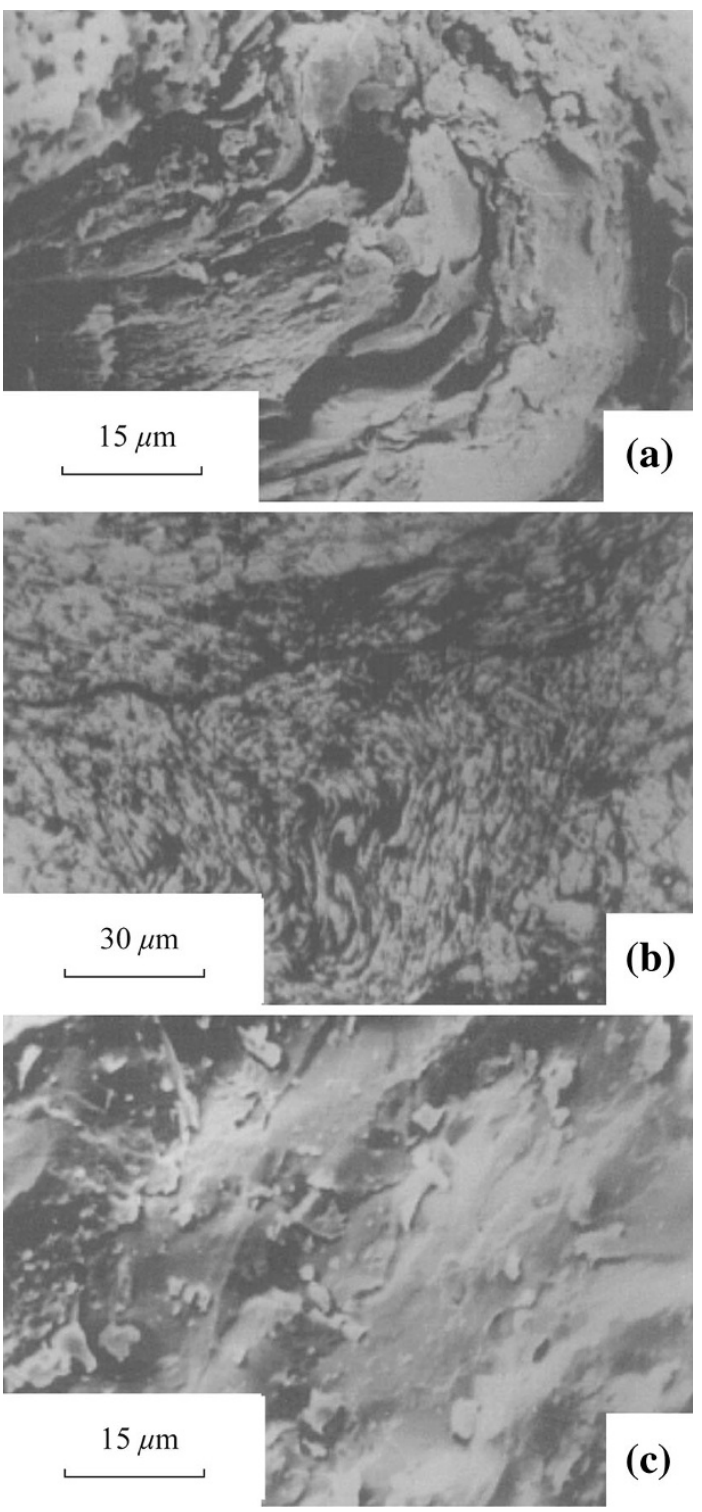

Fig. 5 The series of ductile deformations include. a Wrinkle structure coal; b Mylonitic structure coal; and c Ductile structure coal

and pressure conditions. The flow volumes of gases under pressures of $0.5,1.0,1.5,2.0,2.5,3.0,3.5,4.0,4.5$, 5.0 MPa were successively tested, after which the gas and water single-phase permeability $\left(\mathrm{K}_{\mathrm{g}}, \mathrm{K}_{\mathrm{w}}\right)$ of each point, along with the Klinkenberg permeability $\left(\mathrm{K}_{0}\right)$, were calculated.

\section{Results and discussion}

4.1 Metamorphic and deformed environments of TDC

The Huaibei and Huainan coal mining areas have suffered from multi-phase complicated structural and magma-thermal 
Table 1 The characteristics of structural parameters of tectonically deformed coals

\begin{tabular}{|c|c|c|c|c|c|c|c|c|c|c|c|}
\hline \multirow[t]{2}{*}{$\begin{array}{l}\text { Type of tectonically } \\
\text { deformed coals }\end{array}$} & \multirow[t]{2}{*}{$\begin{array}{l}\text { Coal } \\
\text { sample } \\
\text { ID }\end{array}$} & \multicolumn{2}{|c|}{$\begin{array}{l}\text { Vitrinite } \\
\text { reflectance } \\
(\%)\end{array}$} & \multicolumn{2}{|l|}{ NMR } & \multirow{2}{*}{$\begin{array}{l}\text { EPR } \\
N_{\mathrm{g}} \times 10^{18} \\
\text { Spins }(\mathrm{g})\end{array}$} & \multicolumn{5}{|l|}{ XRD } \\
\hline & & $\overline{R_{\mathrm{o}, \max }}$ & $\overline{R_{\mathrm{O}, \mathrm{bi}}^{*}}$ & $\overline{f_{\mathrm{a}}(\%)}$ & $\overline{\mathrm{H}_{\mathrm{fa}} / \mathrm{H}_{\mathrm{fal}}}$ & & $d_{002}(\mathrm{~nm})$ & $L_{\mathrm{c}}(\mathrm{nm})$ & $L_{\mathrm{a}}(\mathrm{nm})$ & $d_{\mathrm{r}}(\mathrm{nm})$ & $L_{\mathrm{a}} / L_{\mathrm{c}}$ \\
\hline \multirow[t]{2}{*}{ Cataclastic structure coal } & QN03 & 1.23 & 0.33 & & & 75.03 & 0.3667 & 1.3755 & 1.8575 & 0.568 & 1.35 \\
\hline & HZ01 & 2.97 & 0.58 & 0.873 & & 107.78 & 0.3537 & 2.0291 & 2.4107 & 0.485 & 1.19 \\
\hline \multirow[t]{2}{*}{ Mortar structure coal } & TY02 & 1.51 & 0.32 & & & 44.89 & 0.3662 & 1.4903 & 1.8546 & 0.535 & 1.24 \\
\hline & $\mathrm{XY} 02$ & 1.99 & 0.44 & & & 45.51 & 0.3699 & 1.2997 & 1.8444 & 0.561 & 1.42 \\
\hline Granulitic structure coal & XY01 & 1.26 & 0.31 & & & 33.87 & 0.3665 & 1.4379 & 1.9163 & 0.540 & 1.33 \\
\hline Mealy structure coal & ZXZ06 & 1.33 & 0.28 & & & 65.79 & 0.3561 & 1.5138 & 2.0003 & 0.528 & 1.32 \\
\hline \multirow[t]{3}{*}{ Schistose structure coal } & ZJ01 & 0.95 & 0.23 & 0.791 & 3.109 & 52.43 & 0.3828 & 0.9011 & 1.7254 & 0.613 & 1.91 \\
\hline & LH05 & 1.75 & 0.38 & 0.802 & 3.191 & 61.20 & 0.3617 & 1.5694 & 2.0895 & 0.538 & 1.33 \\
\hline & TT10 & 1.94 & 0.40 & 0.799 & 3.187 & 41.94 & 0.3619 & 1.566 & 1.9791 & 0.534 & 1.26 \\
\hline Thin-layer structure coal & XJ03 & 1.01 & 0.23 & & & 44.15 & 0.3716 & 0.928 & 1.8524 & 0.592 & 2.00 \\
\hline Scaly structure coal & LL01 & 1.45 & 0.43 & 0.795 & 3.419 & 64.08 & 0.3659 & 1.3645 & 1.8997 & 0.535 & 1.39 \\
\hline Wrinkle structure coal & BJ05 & 1.08 & 0.24 & 0.778 & & 36.12 & 0.3716 & 1.0827 & 1.7684 & 0.57 & 1.63 \\
\hline \multirow[t]{2}{*}{ Mylonitic structure coal } & ZXZ04 & 1.82 & 0.41 & 0.809 & & 136.91 & 0.3684 & 1.4733 & 1.9754 & 0.558 & 1.27 \\
\hline & HZ07 & 3.59 & 0.71 & 0.925 & 13.80 & 84.38 & 0.3497 & 2.5172 & 2.4489 & 0.467 & 0.97 \\
\hline
\end{tabular}

Broad horizontal lines in the table distinguish tectonically deformed coals formed in different metamorphic and deformational environments; narrow horizontal lines distinguish tectonically deformed coals of different deformational series

$* R_{\mathrm{o}, \mathrm{bi}}=R_{\mathrm{o}, \max }-R_{\mathrm{o}}$, min $; f_{\mathrm{a}}$ carbon aromaticity; $L_{\mathrm{c}}$ the stacking of basic structural units; $L_{\mathrm{a}}$ extension of basic structural units; $d_{002}$ the spacing among mono-layers of aromatics; $d_{\mathrm{r}}$ the aliphatic spacing; $N_{\mathrm{g}}$ radical density

activities (Figs. 1, 2). As a result, under different metamorphic and deformed environments, various kinds of TDC have formed in these mining areas (Yao and Lu 1996; Jiang et al. 2001; Ju and Wang 2002; Ju 2003). With regard to the deformational characteristics of TDC (Table 1), three kinds of metamorphic and deformed environments were recognized in the Huaibei and Huainan coal mining areas. The first type is the metamorphic and deformed environments of the low-rank coals $\left(R_{\mathrm{o}, \max }<1.30 \%\right)$, which are related to plutonic metamorphism; the second one is the metamorphic and deformed environments of the middle-rank coals $\left(1.30<R_{\mathrm{o}, \max }<2.00 \%\right)$, which result from plutonic metamorphism and superimposed magmatic thermal and dynamic metamorphism; the third one is the metamorphic and deformed environments of the high-rank coals $\left(R_{\mathrm{o}, \max }>2.00 \%\right)$, due to plutonic metamorphism and a superimposed, stronger magmatic thermal and dynamic metamorphism.

\subsection{Micro-structural evolution in different types of TDC}

There has been speculation (Cao et al. 2000) as to how stress affects the optical properties of coal and whether chemical change happens when the physical structure of deformed coal changes. Based on the present study, three models were proposed to interpret the influence of tectonic stress on the dynamic evolution of organic matter, including friction heat, strain energy and mechanicalchemistry mechanism.

In the brittle deformed coal, macromolecular structural features of different TDC are different. As the brittle deformation becomes strong (Fig. 3), coal macromolecular structures can transform from a cataclastic structure coal, mortar structure coal, or granulitic structure coal to a mealy structure coal, and can also transform from schistose structure coal to thin-layer structure coal. With the increase of tectonic stress, the structural fractures quickly spread along the weak belts of bond forces; the coal body then breaks and blocks and particles glide, rotate and displace. Friction heat is then produced, which promotes local coal metamorphism. According to the observations of XRD, HRTEM and the highest bireflectance in shear zones (Table 1), frictional heating or stress-chemistry of shearing strain areas might play a more important role in increasing brittle deformation than the area with low or no strain. This is because the rate of strain is high enough to destroy bond forces in the stress direction, generate thermal energy and locally alter coal structure when tectonic stress increases.

It is obvious that the effect of tectonic stress is not the same for different kinds of ductile deformation coals (Fig. 5). There are three main types of changes in 
macromolecular structures for TDC: dislocation glide between the aromatic layers of coal cores, shear glide of the aromatic cores, and destruction/recombination of the molecular structure bonding energy. The changes in macromolecular structure in ductile deformation become greater than in brittle deformation. Superimposition of various types of macromolecular structure change is, therefore, the basic process of coal structure shearing and also the essential process of strong ductile deformation coals. These findings are consistent with the hypothesis of aromatic lamellae growing and reorienting, as proposed by Levine and Davis (1989), and the strain energy transformation, presented by Bustin et al. (1995) and Ross and Bustin (1990).

Since deformation is the result of strain effects in coal, the chemical coalification derived from deformation should be attributable to the strain. During deformation of a coal seam, strain might play several distinct roles, depending upon the strain rate and the geological setting. In strong ductile shearing condition resulting from lower strain rate, the reorientation of aromatic lamellae responsible for higher bireflectance or biaxial vitrinite reflectance anisotropy may occur without brittle failure. In this case, coal would deform in a ductile way and the aromatic lamellae would become oriented with the new stress regime (Cao et al. 2000; Ju et al. 2005a; Li et al. 2011, 2013). A progressive strain may tend to flatten pore spaces and shorten the distance between lamellae. If the rearrangement of lamellae was slow enough, then all of the chemical structural units might conform to the new stress setting without chemical change. If the coal were pulverized to a fine grain size by ductile shearing, grain flow would parallel the stress direction. During grain flow, strain would be translated to particle surfaces, thus causing thin areas of strain. Changes in the coal physical and chemical structure might occur on the particle surface, where local changes in coalification might be produced. Strain rearrangement of aromatic lamellae on the particle surfaces would lead to local coalification (Cao et al. 2000). The degree to which strain rearrangement translates to the particle interior may have a profound influence on the gross change in coal structure. Greater strain on the particle surface not only causes reorientation of aromatic lamellae, but also may arouse some chemical change.

The observation that the highest bireflectance occurs in shear zones has been shown from anthracite specimens deformed at a high temperature and pressure (Bustin et al. 1995). Thus, it is suggested that strain energy might play a more significant role than frictional heating in increasing coal deformation and metamorphism. The main reason is that the rate of strain is insufficient to generate temperatures high enough to alter coal.
4.3 Structural effects on physical properties in different types of TDC

Different mechanisms of deformation could have a contrasting influence on various types of TDC macromolecular structure. Deformations of the macromolecular structure may induce changes of the pore structure and these would impact the physical properties of reservoirs (porosity and permeability). In this section, we will discuss the alteration of porosity and permeability induced by the deformation of coal structure in different deformation mechanisms.

\subsubsection{Porosity of TDC reservoirs and their relation to structure}

Coal contains large numbers of pores (Gan et al. 1972; Zhang et al. 1996; Gürdal and Yalçin 2001), and even more in TDC. The pore types of TDC were obviously distinct from those of primary structure coals. According to the average pore diameter, the nano-scale pores of TDC have been divided into four types: mesopores $(15-100 \mathrm{~nm})$, micropores $(5-15 \mathrm{~nm})$, sub-micropores $(2.5-5 \mathrm{~nm})$, and ultra-micropores $(<2.5 \mathrm{~nm})(\mathrm{Ju} 2003$; Ju et al. 2005a).

In this study, the parameters of pore structure were analyzed on the basis of the experimental results shown in Table 2. Research was performed on the nano-scale pore structure of the metamorphic-deformed environments of low-rank coal and the different deformational series of structural coal. For the metamorphic-deformed environment of low-rank coal, both the pore volumes and pore surface areas of the mesopores and the pores $<15 \mathrm{~nm}$ emerge decrease and increase tendencies, respectively. Some sub-micropores and ultra-micropores can be found in this series of coals; For TDC formed in the metamorphicdeformed environments of middle and high-rank coal, pore structure change is basically consistent with the metamorphic-deformed environments of low-rank coal.

On the basis of the results in Table 2, the pore structure, such as pore diameter, pore volume and specific surface area, are obviously influenced by changes of temperature. In addition, the tectonic stress results in variability in porosity. Brittle deformation and ductile deformation can change the structural parameters of coal pores, but the pore structure different kinds of TDC are obviously different. The volume and specific surface area of nano-scale pores $(<5 \mathrm{~nm})$ in TDC are larger than those of normal coals. This finding indicates that TDC have a higher adsorption capability of TDC reservoirs. On the other hand, Zhang et al. (1996) and Ju et al. (2004) have demonstrated that the volume and specific surface area of macro- and medium pores of TDC have a similar variation and reveal stronger laminar flow. 
Table 2 The characteristics of pore structural parameter of tectonically deformed coals

\begin{tabular}{|c|c|c|c|c|c|c|c|c|c|c|c|}
\hline \multirow{2}{*}{$\begin{array}{l}\text { Type of tectonically } \\
\text { deformed coals }\end{array}$} & \multirow{2}{*}{$\begin{array}{l}\text { Coal } \\
\text { sample ID }\end{array}$} & \multicolumn{5}{|c|}{ Pore volume } & \multicolumn{5}{|c|}{ Pore specific surface area } \\
\hline & & $V_{\mathrm{t}}\left(\mathrm{cm}^{3} / \mathrm{g}\right)$ & $V_{4} / V_{\mathrm{t}}$ & $V_{5} / V_{\mathrm{t}}$ & $V_{6} / V_{\mathrm{t}}$ & $V_{7} / V_{\mathrm{t}}$ & $S_{\mathrm{t}}\left(\mathrm{m}^{2} / \mathrm{g}\right)$ & $S_{4} / S_{\mathrm{t}}$ & $S_{5} / S_{\mathrm{t}}$ & $S_{6} / S_{\mathrm{t}}$ & $S_{7} / S_{\mathrm{t}}$ \\
\hline \multirow[t]{2}{*}{ Cataclastic structure coal } & QN03 & 0.00046 & 95.652 & 4.348 & & & 0.484 & 83.33 & 16.667 & & \\
\hline & HZ01 & 0.00049 & 81.663 & 8.163 & 10.204 & & 0.105 & 43.810 & 10.476 & 45.714 & \\
\hline \multirow[t]{2}{*}{ Mortar structure coal } & TY02 & 0.00079 & 78.481 & 11.392 & 7.595 & 2.532 & 0.224 & 30.357 & 21.429 & 27.678 & 20.536 \\
\hline & XY02 & 0.00055 & 92.727 & 5.455 & 0 & 1.818 & 0.072 & 59.722 & 16.667 & 8.333 & 15.278 \\
\hline Granulitic structure coal & XY01 & 0.00229 & 81.223 & 13.100 & 5.240 & 0.437 & 0.491 & 43.789 & 28.31 & 26.28 & 1.221 \\
\hline \multirow[t]{3}{*}{ Schistose structure coal } & ZJ01 & 0.00066 & 86.364 & 7.576 & 6.060 & & 0.123 & 46.341 & 15.447 & 38.212 & \\
\hline & LH05 & 0.00093 & 94.624 & 4.301 & 1.075 & & 0.101 & 72.277 & 12.871 & 14.852 & \\
\hline & TT10 & 0.00090 & 96.667 & 3.333 & & & 0.081 & 85.185 & 13.580 & 1.2350 & \\
\hline Thin-layer structure coal & XJ03 & 0.00491 & 70.061 & 18.534 & 11.202 & 0.203 & 1.377 & 25.853 & 28.467 & 44.080 & 1.600 \\
\hline Scaly structure coal & LL01 & 0.00215 & 82.791 & 10.698 & 6.511 & & 0.464 & 41.164 & 22.845 & 35.991 & \\
\hline Wrinkle structure coal & BJ05 & 0.00407 & 76.167 & 17.700 & 6.143 & & 1.008 & 37.401 & 33.929 & 28.670 & \\
\hline \multirow[t]{2}{*}{ Mylonitic structure coal } & ZXZ04 & 0.01871 & 74.025 & 19.401 & 6.146 & 0.428 & 4.575 & 33.880 & 34.972 & 27.607 & 3.541 \\
\hline & HZ07 & 0.00882 & 28.458 & 14.286 & 54.875 & 2.381 & 6.365 & 5.027 & 10.008 & 79.214 & 5.751 \\
\hline
\end{tabular}

$V_{4} 15-100 \mathrm{~nm} ; V_{5} 5-15 \mathrm{~nm} ; V_{6} 2.5-5 \mathrm{~nm} ; V_{7}<2.5 \mathrm{~nm} ; V_{\mathrm{t}}$ Total pore volume; $S_{4} 15-100 \mathrm{~nm} ; S_{5} 5-15 \mathrm{~nm} ; S_{6} 2.5-5 \mathrm{~nm} ; S_{7}<2.5 \mathrm{~nm} ; S_{\mathrm{t}}$ Total specific surface area

Thermal and stress action can facilitate coalification and change the macromolecular structure and nano-scale pore structure of TDC (Qin et al. 1995; Cao et al. 2003). However, the behavior and degree of changes are distinct. With the increase of temperature, meso- and micro-molecules can be arranged to recomposition and condensation by means of physical resultant force. The increase in degree of ordering is random in orientation to the aromatic layers that remain thin. This commonly enhances the thermal stability of the aromatic structure. Because the aromatic layers are disordered, a more concentrated arrangement results in the formation of mesopores and micropores, forming a hole or holes which connected by pores. Under tectonic stress, the amount of coal macromolecules increases continuously. Additionally, the bordering aromatic rings continue to polymerize and form superpositions. The local directional structure occurs in non-directional aromatic layers, and then the directional structure extends to the entire area. The relevant mechanism is that the dislocation of the aromatic cores and slippage of aromatic layers must occur. The larger pores are formed between the aromatic cores and aromatic layers. The pores mainly consist of micropores and sub-micropores, but ultra-micropores are also formed. The connectivity of pores, however, becomes worse due to the structural deformation. In the local directional processes of aromatic structure units, special thin-necked and bottleshaped pores have developed. These are mainly built up by pores between the directional and un-directional structure units.

\subsubsection{Permeability of TDC reservoirs and their roles in CBM exploitation}

TDC with early low ductile deformation is followed by brittle deformation, gas phase permeability in the range of $0.1-5.0 \times 10^{-3} \mu \mathrm{m}^{2}$ (which is the same or higher than that of primary structure coals) and TDC with weak deformation (Ju et al. 2012; Fig. 6), gas phase permeability would decrease. This disagree with the common understanding that the permeability of the area where TDC develop is low.

Several types of TDC could also appear vertically to the coal bed in some regions. As studying the in situ permeability of the coal bed, it is significant to get representative samples of each type of coal in order to obtain integrative permeability. Because of the heterogeneous characteristics of the coal seams, especially in the area of TDC development, we may predict a permeability change of the TDC according to the coal types present and adjust degasification styles accordingly.

As the tectonic stress increases, the coal is further crushed into cataclastic-angular and/or cataclastic-granular pieces. Original cleats that are completely covered with deformation (Karacan and Okandan 2000; Su et al. 2001; Jiang et al. 2004) may wrench and tightly compress the fractures, even grinding the coals. Locally intensive deformation may also wrench and tightly compress the fractures, grinding coal into powder, which may plug sheared fractures. However, a combination of the original cleats and tectonic-induced fractures with the deformation 

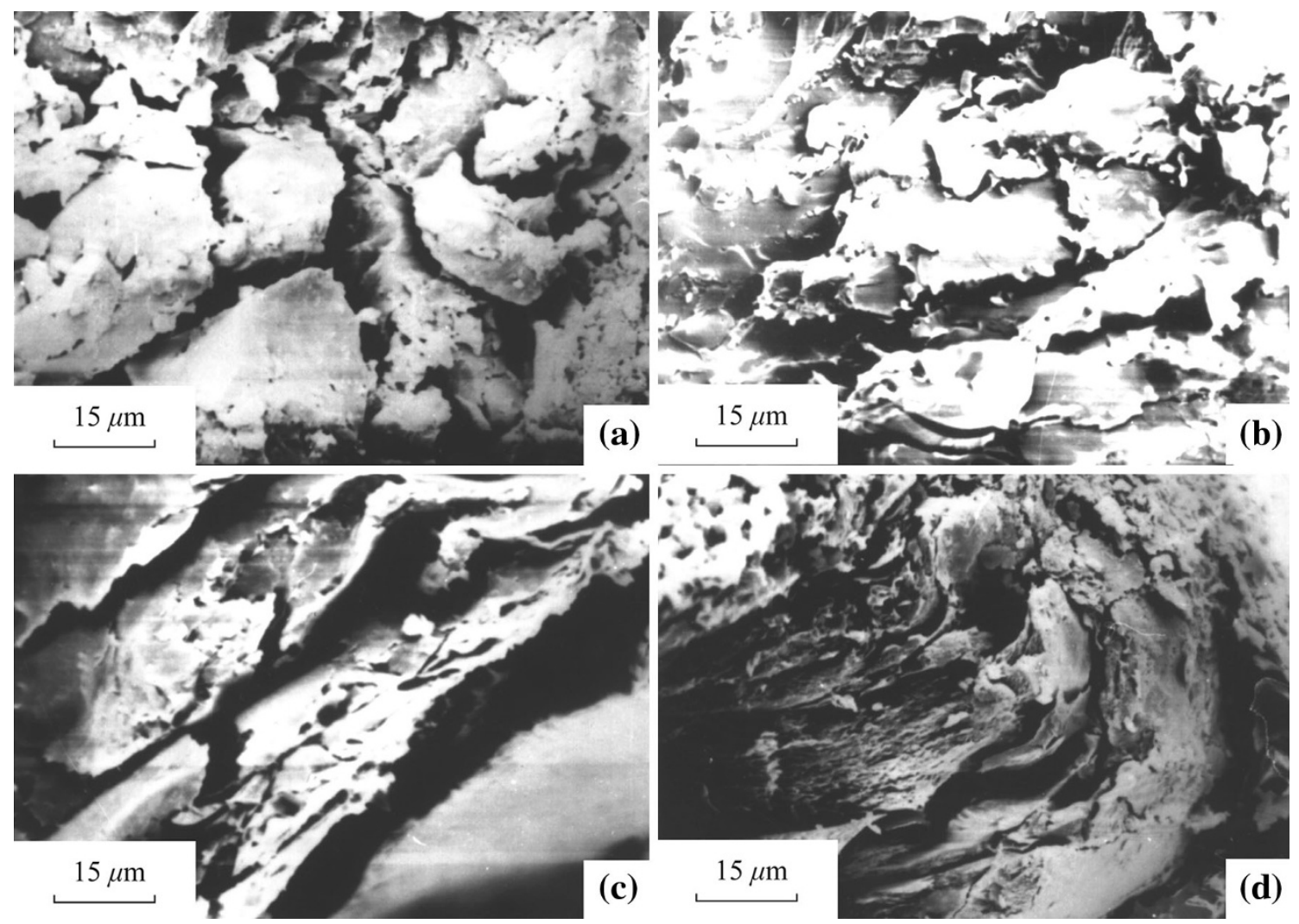

Fig. 6 SEM and optical microscopy image of TDC (Ju et al. 2012). a Cataclastic structure coal, multi-directional fracture cutting, and no obvious displacement in the blocks, SEM; b Mortar structure coal, multi directional fracture cutting, and obvious displacement in the blocks, SEM; c Schistose structure coal, single directional fracture, and little displacement on its surface, SEM; d Wrinkle structure coal, coal was wrinkled, and later superimposed by brittle fractures, SEM

style (brittle or ductile), size, continuity and connectivity of the sheared fractures, contributes significantly to the overall permeability of TDC. It is, therefore, likely to have a major role in the flow of methane through structurally deformed coal in both diffusion at the micropore level and laminar flow at the cleat level (Jiang et al. 2004; Li et al. 2013).

In general, cataclastic coals or schistose coals are formed through a brittle deformation mechanism. These types of coal have a hierarchy of open, continuous and connecting fractures and cleats. The effective block size of all those space is not defined at present, but is somewhere between cleats and micro-fractures (Karacan and Okandan 2000; Su et al. 2001; Jiang et al. 2004). A large number of brittle fractures in TDC under shearing condition will make methane migration occur faster than in primary structure coals. This tendency is extremely important for the development of CBM and may not only preserve significant gas reservoirs, but also increase the inherent permeability.

Nevertheless, not all TDC possess the properties of fast desorption and laminar flow. Ductile deformed coals (such as mylonitic coals, which are locally generated in an intensively compressive and shearing environment) always display tightly compressed and broken fractures that are pushed into one another, leading to worse connectivity for methane migration.

A few TDC reservoirs, especially schistose, mortar and cataclastic structure coals subjected to a certain degree of brittle fractures, have good exploration and development potential for CBM. Low ductile deformations, superimposed by later brittle deformations, also have high potential. In addition, changes in coal seam structure, due to structural stress and the destruction of coal structures caused by the rheology of coal seams, are the major factors resulting in the gas outbursts of coalmines (Hao et al. 2000; Diaz Aguado and Nicieza 2007). Therefore, according to the intensity, type and distribution of TDC reservoirs, the zone of CBM accumulation and gas outbursts could be predicted. TDC reservoirs with strong brittle-ductile and ductile deformation, such as scale structure coal and mylonitic structure coal, have strong relationship with preventing and controlling coal and gas outbursts and gas emissions. These problems urgently need to be resolved. 


\section{Conclusions}

Based on the comprehensive evaluation of coal samples from Huaibei and Huainan coalfields in southern North China, the structure characteristics of tectonically deformed coals (TDC) and their influence on the physical properties of coals have been discussed. Primary conclusions are summarized as follows:

(1) Under the directional stress, BSU arrangement is increased and closer, and the orientation is stronger from brittle deformed coal to ductile deformed coal. Under the effect of oriented stress, the orientation of the macromolecular structure becomes locally stronger, and the ordering degree of the arrangement of the BSU is obviously enhanced.

(2) Structural deformation directly influences the macromolecular structure of coal, which results in dynamic metamorphism. In the brittle deformed coal, frictional heating and stress-chemistry of shearing areas might play a more important role in increasing brittle deformation. This is because the rate of strain is enough to generate high temperatures, locally altering coal structure under stress. In ductile deformation coals, strain energy might play a more important role than frictional heating in increasing coal deformation and metamorphism, because the rate of strain is insufficient to generate temperatures high enough to alter coal.

(3) The nano-scale pore volume of the cataclastic coal structure caused by brittle deformation consists mainly of mesopores, while mesopores volume in ductile deformed coal diminishes rapidly along with an increase in the proportion of micropores and submicropores. Ductile deformation coal has similar characteristics to the weak brittle deformation coals, but sub-micropores and ultra-micropores are present in brittle deformation coal. The main factor that produces a change in pore structure is strong structural deformation. Brittle and ductile deformation can change the pore size distribution, which in turn changes spacing and chemical structure.

(4) The permeability of TDC can be high. The permeability increases sequentially, beginning with cataclastic structure coal, to mortar structure coal, to schistose structure coal that is vertical to the fracture and, finally, to schistose structure coal that is parallel to the fracture. The permeability of TDC where low ductile deformation was superimposed by later brittle deformation is better than primary structural coal.

This work has implications for CBM potential and also for mining health and safety. By understanding the mechanisms that cause the increase of micro- and nanoporosity and permeability in CBM reservoirs these reservoirs can be more effectively identified, explored and developed. Additionally, high yield areas of specific reservoirs can be more easily targeted. Finally, because the mechanisms that affect porosity and permeability also lead to the development of gas pooling and weakened areas in the coal structure outburst prone areas can be identified, and degasification and gas management technology can be developed and specialized, drastically increasing safety in gassy and outburst prone mines.

Acknowledgments This work is supported by the National Natural Science Foundation of China (Grant No. 40772135; 40972131; 41030422), the Strategic Priority Research Program of the Chinese Academy of Sciences (XDA05030100), and National Science and Technology Major Project (No. 2011ZX05060-005).

Open Access This article is distributed under the terms of the Creative Commons Attribution License which permits any use, distribution, and reproduction in any medium, provided the original author(s) and the source are credited.

\section{References}

Bustin RM (1983) Heating during thrust faulting in the rocky mountain: friction or fiction? Tectonophysics 95:309-328

Bustin RM, Ross JV, Rouzaud JN (1995) Mechanisms of graphite formation from: kerogen: experimental evidence. Int J Coal Geol 28:1-36

Cao YX (1999) Tectonically deformed coal: its physicochemical properties and mining hazards. $\mathrm{PhD}$ thesis, Peking University, Beijing, p 124-133 (In Chinese)

Cao YX, Mitchell GD, Davis A, Wang DM (2000) Deformation, metamorphism of bituminous and anthracite coals from China. Int J Coal Geol 43:227-242

Cao DY, Zhang SR, Ren DY (2002) Theinfluence of structural deformation on coalification: a case study of carboniferous coal measures in the northern foothills of the Dabie orogenic belt. Geol Rev 48(3):313-317 (In Chinese)

Cao YX, Davis A, Liu RX, Zhang Y (2003) The influence of tectonic deformation on some geochemical properties of coals-a possible indication of outburst potenial. Int J Coal Geol 53:69-79

Castro MF, Lobodin VV, Rodgers RP et al (2012) A molecular model for illinois no. 6 Argonne premium coal: moving toward capturing the continuum structure. Fuel 95:35-49

Diaz Aguado MB, Nicieza CG (2007) Control and prevention of gas outbursts in coal mines, Riosa-Olloniego coalfield Spain. Int $\mathbf{J}$ Coal Geol 69:253-266

Evans H, Brown KM (1973) Coal structures in outbursts of coal and firedamp conditions. Min Engg 132(148):171-179

Fowler P, Gayer RA (1999) The association between tectonic deformation, inorganic composition and coal rank in the bituminous coals from the South Wales coalfield United Kingdom. Int J Coal Geol 42:1-31

Gan HS, Nandi SP, Walker PL (1972) Nature of the porosity in American coals. Fuel 51(4):272-277

Green U, Aizenshtat Z, Gieldmeister $\mathrm{F}$ et al (2011) $\mathrm{CO}_{2}$ adsorption inside the pore structure of different rank coals during low temperature oxidation of open air coal stockpiles. Energy Fuel 25(9):4211-4215 
Gregg SJ, Sing KSW (1982) Adsorption surface area and porosity, 2nd edn. Academic Press, London, p 32-150, 290-330

Gürdal G, Yalçin MN (2001) Pore volume and surface area of the Carboniferous coals from the Zonguldak basin (NW Turkey) and their Variations with rank and maceral composition. Int J Coal Geol 48:133-144

Han DX (1996) China coal petrology. China University of Mining and Technology Press, Xuzhou

Hao JH, Yan CF, Zhang ZX (2000) The tectonic coal and its effects on coal gas outburst. J Jiaozho Inst Technol 19(6):403-406 (In Chinese)

Hower JC (1997) Observation on the role of Bernice coal field (Sullivan County, Pennsylvania) anthracite in the development of coalification theories in the Appalachians. Int J Coal Geol 33:95-102

Jiang B, Qin Y (1998) Evolution mechanism of structures of deformed coal and its geological significance. China University of Mining and Technology Press, Xuzhou (In Chinese)

Jiang B, Qin Y, Fan BH, Fu XH, Sang SX, Hu C (2001) Physical property of coal reservoir and exploration prospects for coal bed methane in Huaibei area. J China Univ Min Technol 30(5):433-437 (In Chinese)

Jiang B, Ju YW, Qin Y (2004) Textures of tectonic coals and their porosity. In: Yuehan Wang, Shirong Ge, Guangli Guo (eds) Mining science and technology. Balkema, Rotterdam, pp 315-320

Ju YW (2003) Characteristics of structural evolution and physical properties of reservoirs of tectonically deformed coals and theirs action mechanism. PhD thesis, China University of Mining and Technology, Xuzhou, pp 37-87, 150-153 (In Chinese)

Ju YW, Li XS (2009) New research progress on the ultrastructure of tectonically deformed coals. Prog Nat Sci 19:1455-1466

Ju YW, Wang GL (2002) Rheology of coal seams and their relation with gas outbursts: a case study of the Haizi coal mine Huaibei coalfield. Geol Rev 48(1):96-105 (In Chinese)

Ju YW, Wang GL, Jiang B, Hou QL (2004) Microcosmic analysis of ductile shearing zones of coal seams of brittle deformation domain in superficial lithosphere. Sci China Ser D 47(5):393-404

Ju YW, Jiang B, Hou QL, Wang GL (2005a) Relationship between nano-scale deformation of coal structure and metamorphicdeformed environments. Chin Sci Bull 50(16):1784-1795

Ju YW, Jiang B, Hou QL, Wang GL, Ni SQ (2005b) ${ }^{13}$ C NMR spectra of tectonically deformed coals and the effects of stress on structural components. Sci China Ser D 48(9):1418-1437

Ju YW, Jiang B, Wang GL, Hou QL (2005c) Tectonic coals: structures and physical properties of reservoirs. China University of Mining and Technology Press, Xuzhou, pp 1-244

Ju YW, Yan ZF, Li XS, Hou QL, Zhang WJ, Fang LZ, Yu LY, Wei MM (2012) Structural characteristics and physical properties of tectonically deformed coals. J Geol Res, Article ID 852945, p 14

Karacan CÖ, Okandan E (2000) Fracyure/cleat analysis of coals from Zonguldak Basin (northwestern Turkey) relative to the potential of coalbed methane production. Int J Coal Geol 44:109-125

Levine JR, Davis A (1989) The relationship of coal optical fabrics to Alleghanian tectonic deformation in the central Appalachian foldand-thrust belt Pennsylvania. Geol Soc Am Bull 101:1333-1347

Li K, Zhong DL (1992) Microstructures of coal and their relation with gas outbursts - a case study of the Yutianbao coal mine Nantong. Acta Geol Sin 66(2):148-157
Li XS, Ju YW, Hou QL, Lin H (2011) Spectrum research on metamorphic and deformation of tectonically deformed coals. Spectrosc Spectr Anal 31:2176-2182 (in Chinese)

Li XS, Ju YW, Hou QL, Lin H (2012) Spectra response from macromolecular structure evolution of tectonically deformed coal of different deformation mechanisms. Sci China Ser D 55(1):1-11

Li XS, Ju YW, Hou QL, Fan JJ (2013) Response of macromolecular structure to deformation in tectonically deformed coal. Acta Geol Sin 87(1):82-90 (English Edition)

Nishioka M (1992) The associated molecular nature of bituminous coal. Fuel 71:941-948

Qin Y (1994) Micropetrology and structural evolution of high-rank coals in P. R. China. China University of Mining \& Technology Press, Xuzhou, pp.91-94 (In Chinese)

Qin Y, Xu ZW, Zhang J (1995) Natural classification of the high-rank coal pore structure and its application. J China Coal Soc 20(3):265-271 (in Chinese)

Ross JV, Bustin RM (1990) The role of strain energy in creep graphitization of anthracite. Nature 343(4):58-60

Stone IJ, Cook AC (1979) The influence of some tectonic structures upon vitrinite reflectance. J Geol 87(5):479-508

Su X, Feng Y, Chen J, Pan J (2001) The characteristics and origins of cleat in coal from Western North China. Int J Coal Geol 47:51-62

Suchy V, Frey M, Wolf M (1997) Vitrinite reflectance and shearinduced graphitization in orogonic belts: a case study from Kanderstey area, Helvetic Alps Switzerland. Int J Coal Geol 34(1-2): $1-20$

Teichmüller M (1987) Organic material and very low-grade metamorphism. In: Frey M (ed) Low temperature metamorphism. Blackie \& Son Ltd., London, pp 114-161

Teichmüller M, Teichmüller R (1966) Geological causes of coalification. Coal Sci Adv Chem Ser. 55:133-155

Wang YA, Yang SJ (1980) Some characteristics of coal seam with hazard of outburst. J China Coal Soc 1:47-53 (in Chinese)

Wang GL, Zhu YM (1988) Study on the rheology of coal bed. J China Univ Min Technol 3:16-25 (in Chinese)

Wang GL, Cao DY et al. (1992) Thrust nappe, extensional gliding nappe and gravity gliding structures in the southern part of North China, in Addition on the research methods of de-collement. China University of Mining \& Technology Press, Xuzhou. pp. 62-86 (in Chinese)

Wang GL, Jiang B, Cao DY et al (1998) On the Xuzhou-Suzhou arcuate duplex-imbricate fan thrust system. Acta Geol Sin 72(3):228-236 (in Chinese)

Xu LJ, Liu CL, Xian XF (2004) Fractal structure and properties of coal in outburst zone. Chongqing University Press, Chongqing

Yao DX, Lu J (1996) Study on pority of coal from the first mine, Xiejiaji Huainan. Coal Geol China 8(4):31-33 (in Chinese)

Yuan CF (1985) Tectonically deformed coal and coal and gas outbursts. Gas Geol started, 45-52 (in Chinese)

Zhang J, Yu B, Tang JX (1996) Study on pore structures of coal seam Blowing out gas. Coal Geol China 8(2):71-74 (in Chinese)

Zickler GA, Smarsly B, Gierlinger N et al (2006) A reconsideration of the relationship between the crystallite size La of carbons determined by X-ray diffraction and Raman spectroscopy. Carbon 44:3239-3246 